\title{
UMA ABORDAGEM DA PARTICIPAÇĀO ESPORTIVA FEMININA
}

\author{
José Geraldo Massucato (*) \\ Mário Hata $\left({ }^{\star \star}\right)$
}

\section{RESUMO}

A participação da Mulher nos esportes vem crescendo cada vez mais, e sempre esteve relacionada a fatores culturais.

Desta forma, esportes antes restritos aos homens, estão sendo incorporados cada vez mais pelas mulheres, como no caso da corrida de longa distância, que recebe hoje uma afluência significativa por parte delas.

UNITERMOS: Mulheres nos esportes.

\section{JOGOS OLÍMPICOS: UM SONHO FEMININO?}

O mundo tem assistido ao crescente envolvimento das mulheres participantes em atividades esportivas (Barbanti, 1986), e em especial através dos Jogos Olímpicos. E neste fenômeno "Jogos Olímpicos" desde o início deste século, tem ocorrido cada vez mais o envolvimento feminino, como se pode observar na tabela 1.
Vários fatores, como político, religioso e econômico, podem vir a colaborar ou a prejudicar o esporte de uma maneira geral e, conseqüentemente, o esporte feminino.

O que se almeja é a ruptura de preconceitos arraigados à nossa cultura para que a mulher possa desenvolver-se integralmente na sociedade.
A participaçāo da mulher no esporte esteve sempre relacionada a fatores sócio-culturais, atłavés do conhecimento de relatos históricos.

Assim como ao crescente número de mulheres participantes, houve uma rápida ascenção nos seus resultados obtidos. Uma das causas deste crescimento feminino no mundo esportivo é uma forte identificação para com o que o esporte pode oferecer: "O 
Homem tem muitas necessidades pessoais e que trabalha para satisfazer estas necessidades" (Lynd, 1939). Quem pratica atividade esportiva, qualquer que seja, desenvolve uma relação muito próxima à sua pessoa e com o momento que está vivendo (Massucato \& Hata, 1988), além de outras qualidades secundárias.

\section{Tabela 1}

Evolução das participações masculinas e femininas em relação aos Jogos Olímpicos da Era Moderna

\begin{tabular}{clcc}
\hline Ano olimpico & Local & Participação masculina & Participação feminina \\
\hline 1896 & Atenas & 295 & -- \\
1900 & Paris & 1066 & 11 \\
1904 & St. Louis & 546 & 8 \\
1908 & Londres & 1998 & 36 \\
1912 & Estocolmo & 2447 & 57 \\
1920 & Antuérpia & 2527 & 64 \\
1924 & Paris & 2939 & 136 \\
1928 & Amsterdã & 2708 & 263 \\
1932 & Los Angeles & 1281 & 127 \\
1936 & Berlin & 3652 & 328 \\
1948 & Londres & 3677 & 385 \\
1952 & Helsinque & 5349 & 518 \\
1956 & Melbourne & 2813 & 371 \\
1960 & Roma & 4859 & 537 \\
1964 & Tóquio & 4854 & 732 \\
1968 & México & 5782 & 844 \\
1972 & Munique & 8485 & 1603 \\
1976 & Montreal & 4915 & 1274 \\
1980 & Moscou & 4625 & 1247 \\
1984 & Los Angeles & 5458 & 1620 \\
1988 & Seul & & no total: mais de 11 mil \\
\hline
\end{tabular}

Em muitas provas do Atletismo e da $\mathrm{Na}$ tação, as diferenças entre resultados masculinos e femininos vêm constantemente diminuindo, paralelamente à evolução do nível técnico feminino e ao crescimento de mulheres que praticam esporte.

O quadro 1 mostra a comparação entre resultados masculinos e femininos até o ano de 1978, e deste período até 1988, em Atletismo, sendo os de natação até 1988, com exceção das provas $800 \mathrm{~m}$ e $1500 \mathrm{~m}$. Os resultados masculinos foram igualados a $100 \%$, enquanto que o" delta" representa o quanto (em porcentagem) os resultados femininos se encontram em relação aos masculinos. 
Quadro 1

Proporção dos resultados femininos em relação aos masculinọs, em valores absolutos. (")

\begin{tabular}{|c|c|c|c|c|c|c|}
\hline \multirow{2}{*}{$\begin{array}{l}\text { Atletismo } \\
\text { Provas }\end{array}$} & \multicolumn{3}{|c|}{ até 1978} & \multicolumn{3}{|c|}{ até 1988} \\
\hline & masc. & fem. & delta & masc. & fem. & delta \\
\hline $100 \mathrm{~m}$ & 9.95 & 10.88 & $90.7 \%$ & 9.83 & 10.49 & $93.9 \%$ \\
\hline $200 \mathrm{~m}$ & 19.83 & 22.06 & $88.8 \%$ & 19.72 & 21.34 & $91.8 \%$ \\
\hline $400 \mathrm{~m}$ & 43.86 & 48.94 & $88.4 \%$ & 43.29 & 47.60 & $90.0 \%$ \\
\hline $800 \mathrm{~m}$ & 1.43 .44 & 1.54 .94 & $88.9 \%$ & 1.41 .73 & 1.53 .28 & $88.6 \%$ \\
\hline $1500 \mathrm{~m}$ & 3.32.16 & 3.56 .0 & $88.8 \%$ & 3.39.46 & 3.52.47 & $89.0 \%$ \\
\hline $3000 \mathrm{~m}$ & 7.35 .2 & 8.27 .12 & $88.6 \%$ & 7.32 .1 & 8.22 .63 & $88.8 \%$ \\
\hline $10000 \mathrm{~m}$ & 27.22.5 & 31.45 .40 & $84.0 \%$ & 27.13.81 & 30.13 .74 & $89.0 \%$ \\
\hline S. altura & 2.33 & 2.01 & $86.3 \%$ & 2.43 & 2.09 & $86.0 \%$ \\
\hline S. Extensão & 8.90 & 7.09 & $79.7 \%$ & 8.90 & 7.52 & $84.5 \%$ \\
\hline A. Peso (a) & 22.15 & 22.32 & $100.8 \%$ & 23.06 & 22.63 & $98.1 \%$ \\
\hline L. Disco (b) & 71.16 & 70.72 & $99.4 \%$ & 74.08 & 76.80 & $103.7 \%$ \\
\hline L. Dardo (c) & 94.58 & 69.32 & $73.3 \%$ & 104.80 & 80.00 & $76.3 \%$ \\
\hline \multirow{2}{*}{$\begin{array}{l}\text { Natação } \\
\text { Provas (d) }\end{array}$} & \multicolumn{3}{|c|}{ Crawl } & \multicolumn{3}{|c|}{ Costas } \\
\hline & masc. & fem. & delta & masc. & fem. & delta \\
\hline $50 \mathrm{~m}$ & 22.11 & 24.98 & $87.0 \%$ & - & - & - \\
\hline $100 \mathrm{~m}$ & 48.42 & 54.73 & $87.0 \%$ & 54.51 & 1.00 .59 & $88.8 \%$ \\
\hline $200 \mathrm{~m}$ & 1.47.25 & 1.57 .55 & $90.4 \%$ & 1.58 .14 & 2.08 .60 & $91.1 \%$ \\
\hline $400 \mathrm{~m}$ & 3.46 .95 & 4.03.85 & $92.5 \%$ & - & - & - \\
\hline $800 \mathrm{~m}$ & 8.15 .58 & 8.47 .66 & $93.5 \%$ & - & - & - \\
\hline $1500 \mathrm{~m}$ & 15.31 .75 & 16.33.95 & $93.3 \%$ & - & - & - \\
\hline \multicolumn{7}{|c|}{$\begin{array}{l}\text { ( }{ }^{\star} \text { modificado de Mellerowicz \& Meller, } 1979, \text { e Mathews } \& \text { Fox, } 1979 . \\
\text { (a) relação de massa do implemento masculino/feminino }=1,8 . \\
\text { (b) relação de massa do implemento masculino/feminino }=2,0 . \\
\text { (c) relação de massa do implemento masculino/feminino }=1,3 . \\
\text { A partir de } 1 \text { de abril de } 1986, \text { passou a vigorar novos regulamentos para construção do dardo masculino. } \\
\text { (d) com exceção das provas de } 800 \mathrm{~m} \text { e } 1500 \mathrm{~m} \text {, todos os resultados das demais são de até } 1988 .\end{array}$} \\
\hline
\end{tabular}

Em geral, os resultados femininos, nas corridas, vāo se afastando à medida que se aumenta a distância, enquanto que na Natação ocorre justamente o contrário.

Nos Arremessos e Lançamentos, o fato dos resultados femininos serem melhores do que os masculinos, pode ser explicado observando-se as relaçōes de massa dos implementós; onde a relação é menor, como no lançamento do dardo, ao delta é também menor.

Não se sabe afirmar ainda, até quando estas diferenças continuarāo a diminuir nestas proporções, e nem até que ponto as diferenças biológicas, que até entāo têm confirmado uma predominância masculina, em termos absolutos, em todas as modalidades, continuarāo marcando este predomínio. 


\section{A SOCIEDADE ESPORTIVA FEMININA}

Desde o tempo dos hominídeos, tanto a posição da mulher quanto a do homem era bem definida: ela era encarregada da coleta, e ele, da caça e de serviços mais pesados. Esta tradição tem se mantido através dos anos até o nosso tempo.

Nas Olimpíadas da Antiguidade, as muIheres eram proibidas, por regulamento, de assistir às competiçōes porque elas não eram consideradas cidadās, sendo quase totalmente excluídas da vida pública, com exceção das cerimônias religiosas. Com isso, somou-se à História algumas páginas em branco pela ausência da atuação feminina.

A primeira participação da mulher na Olimpíada aconteceu em 1900 (vide tabela 1). A partir daí, sua participação cresceu solidamente para ocupar um lugar de honra no mundo do esporte. A primeira Maratona Olímpica feminina aconteceu em 1984, não esquecendo que numa das Olimpíadas da Antiguidade, uma mulher se travestiu de homem para poder participar daquele evento. Com isto: sempre existirão pessoas que se adiantarăo ao tempo. A pseudo preservação da mulher a esforços prolongados pode estar relacionada à cautelosa atitude do Comitê Olímpico Internacional, sabendo-se que muitas competições não-olímpicas de esforços de longa duração já haviam sido desenvolvidas.

Muitas atividades esportivas, até então restritas exclusivamente aos homens, como o salto triplo, estão sendo incorporadas por mulheres, apesar da recomendação para serem evitadas, em função do trabalho bastante intenso para sua execução (Pini, 1978). Algumas destas atividades constituem-se em número ainda reduzido, enquanto que outras (corrida de longa distância, por exemplo) recebem uma afluência bastante significativa.

Pini, 1978, diz que "poder participar de todas as modalidades esportivas praticadas pelo homem, ela pode. Resta apenas sabermos se ela deve fazê-lo"

Dependendo do sistema sócio-políticoeconômico de cada nação, a efetiva participação da mulher no esporte tem sido retardada por um tempo bastante prolongado. Em algumas partes do mundo, as mulheres ainda mantêm tradicionalmente seus papéis, e sua participação no esporte é vista de ma- neira inconveniente e incômoda.

\section{O EMBRIĀO CULTURAL PARA A ATIVIDADE ESPORTIVA}

Desde a mais tenra idade, as meninas não são estimuladas adequadamente, e são muitas vezes impedidas de participar das brincadeiras mais agressivas e atléticas, que são largamente oferecidas aos meninos. Elas perdem uma oportunidade de conhecer e de desenvolver suas potencialidades. Em Oberteuffer \& Ulrich, 1977, depara-se com a seguinte citação. "Ao brincar a criança não somente expressa tudo o que the vai no interior, mas reflete os padrōes culturais que a rodeiam, e revela suas ambiçōes, esperanças e interesses; e sua alegria, exaltação ou desapontamento"

Os meninos quase sempre brincam com bolas, ou com brinquedos de guerra, que oferecem excelentes possibilidades de integração com as atividades físicas, enquanto que as meninas se entretêm com bonecas e brinquedos "passivos" Conseqüentemente, os meninos são mais ativos e conseguem liderança através da força física, enquanto as meninas se dedicam às atividades manipulativas e recebem reconhecimento pela atividade verbal.

\section{A CORRIDA COMEÇA DEVAGAR}

A sociedade custa a absorver e aceitar o fenômeno que está ocorrendo, principalmente no início de seu processo. Este custo -está diretamente relacionado ao fator tempo.

A partir da década de .70 , o fenômeno corrida pedestre teve uma aceitação mundial, como se fosse uma "febre" Houve um crescente número de praticantes desta atividade, de vários tipos: o de fim-de-semana, aquele que pratica por recomendação médica, por convite de amigo, pela veiculação através de meios de comunicação, e outros cujos motivos são variados.

Quase duas décadas passadas, os olhos da sociedade começam a se acostumar com as pessoas correndo pelas ruas e parques, a qualquer hora do dia.

\section{A ATUAÇĀO DA MULHER BRASILEIRA}

No Brasil, a participaçăo da mulher nos esportes não é ainda muito bem aceita. Du- 
rante o período ditatorial (1964-1984), por exemplo, o governo tentou impedir a prática da arte marcial - o judô - pela mulher. De acordo com a ideologia reinante, esta decisão foi tomada sem qualquer prévia consulta às pessoas interessadas ou aos especialistas. Esta atitude parece ter retardado o desenvolvimento do Judô feminino, ao contrário do masculino que tem obtido resultados expressivos a nivel internacional.

Embora com um relativo progresso da participaçāo esportiva feminina, no Brasil, ainda há forte preconceito sem bases científicas. Há preocupação por parte de pais, assim como de namorados a respeito da possibilidade da mulher se "masculinizar" 0 esporte, ao contrário, tem um importante papel na afirmação de valores que possibilitarão a realização pessoal e sentimentos de conquista para ela, mulher.

\section{NA UNIVERSIDADE DE SÃO PAULO}

A partir de um levantamento de informaçōes enfocando-se sobre atitudes sócioculturais da mulher no esporte, na Universidade de São Paulo, por Hata, em 1988, concluiu-se que $88 \%$ das entrevistadas que praticam esporte, fundamentalmente atletismo, atribuíram valores positivos à prática esportiva e apenas $12 \%$, valores negativos juntamente com positivos.

Os argumentos utilizados por elas para justificar sua participaçăo vão desde singulares atitudes comportamentais até os ideais sociais: necessidade de conhecimentos específicos e multidisciplinares sobre o esporte; sociabilização; desenvolvimento de qualidades morais, como objetividade, perseverança, responsabilidade, auto-controle, que auxiliam no auto-conhecimento entre outros.

" A realização do próprio feito, apenas o simples fato do 'eu posso fazê-lo', é significativo no auto-conhecimento de qualquer um. ... o desenvolvimento, alteração e mudança da personalidade acontecem quando - Homem satisfaz as exigências das situaçōes que o cercam, e quando ele interage totalmente como um indivíduo total com tais situaçōes" (in Oberteuffer \& Ulrich, 1977).

Por que elas preferem praticar corrida de longa distância? Pela disponibilidade de horário; autonomia de local, companhia e materiais específicos; pela forma de se expressar (prazer, satisfação pessoal, vontade própria, desenvolvendo atitudes de dedicação, concentração, enfrentar desafios). Além disso, pode-se melhorar o "status social", conquistar objetivos estabelecidos, superando limites pessoais através de força de vontade. Certas situaçōes esportivas podem levar à conscientizaçăo das possibilidades e limites do ser humano, aprendendo a colaborar, participar e competir, e avaliar as suas reais condiçōes.

Jones \& Bailey, 1950, confirmam com "quando os indivíduos ganham 'status' em seu grupo pelo perfeito desempenho de tarefas avaliadas pelo próprio grupo, a personalidade desses indivíduos torna-se mais amistosa, menos apreensiva, e mais autoconfiante"

No tocante à época de iniciação esportiva, infelizmente, nossa estrutura escolar para o desenvolvimento de atividades físicas é bastante deficiente: apenas $20 \%$ daquelas estudantes universitárias entrevistadas iniciaram a prática esportiva mais sistemática durante os últimos anos do primeiro grau; $40 \%$ delas, no segundo grau; e outros $40 \%$, somente na universidade. Os incentivadores principais foram seus próprios professores de educação física (44\%), seus amigos (31\%) e outros estímulos (25\%), como motivar-se a partir de um teste vestibular, ou através de incentivo de um técnico, de um irmão, de um pai.

Em contrapartida aos valores encontrados na Universidade de São Paulo, ressalta-se que o primeiro e marcante contato com o esporte ocorre na infância, através da família com um fator determinante neste envolvimento esportivo (Oberteuffer \& Ulrich, 1977).

Atualmente, apesar do tardio primeiro contato com o esporte das estudantes entrevistadas, este foi importante em suas vidas e efeitos positivos ainda perduram, como " aprender a superar os obstáculos nas situaçőes da vida diária" e "vai ter que dar"

Segundo $38 \%$ das entrevistadas, a prática esportiva provoca um grande entusiasmo, motiva a competir, permite uma melhor preparação, e ajuda na tomada de atitudes objetivas, como "ir até o fim", para conseguir a realização pessoal, dentro de uma convivência harmoniosa com outras pessoas. 


\section{CONCLUSŌES}

Arrematando, em relação às considerações acima mencionadas, o fenômeño esportivo feminino é um dos resultados positivos do processo de evolução e transformação da sociedade humana atual. Cada vez, atividades físicás são incorporadas como meios de exprejsáu das pessoas, assim como novas marcas mundiais são estabelecidas como limites da especialização de privilegiados seres humanos, onde a atuação da mulher se faz presente.

Indubitavelmerite, que uma série de fatores sócio-político-eco.าômicos colabora ou prejudica o esporte de uma maneira geral, e conseqüentemente, o esporte feminino. A evolução cultural só será um ponto positivo se esses fatores estiverem adequadamente ajustados ao ideal. Na complexidade do assunto, com as situaçōes mundiais se alternando constantemente, para uma nação o desenvolvimento cultural é adequado, para outra não.

Sendo assim, na esperança de que as práticas esportivas se tornem um hábito salutar, que haja consciência de sua necessidade e importância; que não seja uma atividade secundária, supérflua; que no país do futebol, haja tantos adeptos das diversas modalidades esportivas, quanto do esporte bretão; que o esporte seja um elemento colaborador à formação educacional do ser humano, como fator prioritário, através de um sólido trabalho de base.

E que, apesar do preconceito que ainda perdura em relação à mulher que pratica esporte, é preciso reverter essa situação!

\section{REFERÊNCIAS BIBBLIOGRÁFICAS}

1 ARENO, W. A mulher no esporte. Arquivos da Escola Nacional de Educação Física, Rio de Janeiro, 49:24-9, 1945.

2 ASTRAND, P-O. Tratado de fisiologia do exercício. 2. ed. Rio de Janeiro, Interamericana, 1980.

3 BARBANTI, V. J. Teoria e prática do treinamento desportivo. São Paulo, Edgard Blücher, 1979.

4 BARBANTI, V. J. Treinamento físico: bases científicas. São Paulo, CLR Balieiro, 1986.

5 BERLIN, $P$. The women athlete. In: BERGER, $F$ et alii. The american women in sport. Massachusetts, Addison-Wesley, 1974.

6 CAGIGAL, J. M. Filosofia del deporte femenino. In: CONGRESSO MUNDIAL DEL DEPORTE FEMENINO, Roma, 1980.

7 CASTELLANI FILHO, L. Ensaio sobre a mulher brasileira face a legislaçāo da educaçāo física e do desporto. Desportos e Lazer. 8:8-21, 1982.

8 DEFOLIGNY, C. Aspectos medicos del deporte femenino. Educación Fisica, 170:36-40, 1981.
9 FERNANDES, R. Jogos olímpicos - citius, altius, fortius. Porto, Porto Editora, 1987

10 GLAUCIO, A. D. S. A mulher nas olimpíadas.CiênciaHoje,SãoPaulo, 8(43):34-43, 1988.

11 HATA, M. Sports in your life, Brazil in Sports and Woman in sports. In: SEMINÁRIO INTERNACIONAL EKIDEN, 1-3, Osaka, 1987 Anais.

12 IAAF-ATFS. Statistics handbook. Seoul Olympic Games, 1988.

13 JONES, M. E. \& BAILEY, N. Physical maturing among boys as related to behavior. Journal of Educational Psychology, 41:129-48, 1950.

$14 \mathrm{KATCH}, \mathrm{F}$ I. \& McARDLE, W. D. Nutriçāo, controle de peso e exercício. 2. ed. Rio de Janeiro, MEDSI, 1984.

15 LENK, M. A mulher no esporte. In: SIMPÓSIO DE CIÉNCIAS DO ESPORTE, 10, São Caetano do Sul, 1982.

16 LYND, R. Knowledge for what? Princeton, Princeton University Press, 1939.

17 MASSUCATO, J. G. \& HATA, M. Considerações da prática esportiva da mulher no contexto sócio-cultural. In: SEMINÁRIO 
INTERNACIONAL EKIDEN, 4, Osaka, 1988.

18 MATHEWS, D. K. \& FOX, E. L. Bases fisioÍ́gicas da educaçāo física e dos deportos. 2. ed. Rio de Janeiro, Interamericana, 1979.

19 MELLEROWICZ, H \& MELLER. Bases fisiológicas do treinamento físico. São Paulo, EPU e EDUSP, 1979.

20 NETTO, A. R. Jogos olympicos de hontem, de hoje e de amanhan. São Paulo, SPES, 1937

21 OBERTEUFFER, D. \& ULRICH, C. Educação física: manual de princíplos para estudantes de educação física. São PauIo, EPU e EDUSP, 1977.

22 ORGANIZAÇÃO DAS NAÇŌES UNIDAS PARA A EDUCAÇÃO, CIÉNCIA E CUL-
TURA Carta internacional da educaçāo física e do esporte. São Paulo, EEFUSP, 1979.

23 PINI, M. C. A mulher no esporte. Revista Brasileira de Educação Física e Desportos, Brasília, 10:18-25, 1971.

24 PINI, M. C. Fisiologia Esportiva. Rio de Janeiro, Guanabara-Koogan, 1978.

(*) Professor Titular do Departamento de Ginástica da Escola de Educação Física da Universidade de São Paulo.

(**) Professor Auxiliar de Ensino do Departamento Técnico Desportivo da Escola de Educaçáo Física da Universidade de São Paulo. 